\title{
Hop Extracts and Hop Substances in Treatment of Menopausal Complaints
}

Authors

Affiliation
Annekathrin M. Keiler, Oliver Zierau, Georg Kretzschmar

Institute of Zoology, Molecular Cell Physiology and Endocrinology, Technische Universität Dresden, Dresden, Germany

\author{
Key words \\ - Humulus lupulus L. \\ - Cannabaceae \\ - menopause \\ - 8-prenylnaringenin \\ - xanthohumol \\ - isoxanthohumol \\ - safety
}

\section{Abstract \\ $\nabla$}

Hop extract is a long used medicinal product and, regarding hormonal activities, in 1999 a number of prenylflavanones have been identified as its major constituents with 8-prenylnaringenin (8PN) being the main active estrogenic compound. There have been several in vivo studies performed that demonstrate the potential of hop extract and the single compound 8-PN to alleviate climacteric symptoms like osteoporosis, vasomotoric complaints, and sexual motivation. On the other hand,

\section{Hop Secondary Metabolites}

Humulus lupulus L. (hop) (Cannabaceae) is wellknown for the usage of female inflorescences such as bitterness, preservative, and a flavoring agent in beer brewing, but at the same time it has a long history as a medicinal herb. Hop baths

received Dec. 20, 2012

revised February 12, 2013

accepted February 16, 2013

Bibliography

DOI http://dx.doi.org/

$10.1055 / \mathrm{s}-0032-1328330$

Published online March 19 2013

Planta Med 2013; 79: 576-579

(c) Georg Thieme Verlag KG

Stuttgart · New York .

ISSN 0032-0943

Correspondence

Annekathrin M. Keiler

Institute of Zoology,

Molecular Cell Physiology and Endocrinology

Technische Universität Dresden

Zellescher Weg 20b

01062 Dresden

Germany

Phone: +4935146334733

Fax: +4935146331923

Annekathrin.Keiler@

tu-dresden.de have been recommended to alleviate gynecological disorders with reference to the frequently observed menstrual disorders in female hop-pickers suggesting an estrogenic mode of action [1]. Its importance as a traditional medicinal herb has also been recognized by the European Medicines Agency EMEA that has published a monograph about its use and safety [2]. Among terpenes and bitter acids, a number of prenylflavanoids secreted by lupulin glands have been identified in the strobiles. In 1999, the investigation of an estrogenically active fraction containing as the main compound xanthohumol $(\mathrm{XH} ; 0.1-1 \%$ in dry hops) but also isoxanthohumol (IX), 6-prenylnaringenin (6-PN), and 8-prenylnaringenin (8-PN; $100 \mathrm{mg} / \mathrm{kg}$ dry hops) (\$ Fig. 1) led to the discovery of 8-PN as the major active constituent, turning out to be the most potent phytoestrogen known to date [1,3-8]. Prior to this, 8-PN or 8isopentenylnaringenin, as it was originally called by its discoverers [9], had already been isolated only a few clinical studies have been performed so far, and these mainly focused on menopausal discomforts, especially hot flushes, yielding rather inconclusive results. Despite preferentially activating estrogen receptor $\alpha, 8$-PN is only slightly uterotrophic, but it also elucidates estrogenic effects on the mammary gland. In conclusion, although hop extract and especially 8-PN are promising candidates as a relief for climacteric symptoms, data on the safety and efficacy is still scarce. 
<smiles>COc1cc(O)c(CC=C(C)C)c(O)c1C(=O)C=Cc1ccc(O)cc1</smiles>

Xanthohumol (XH)

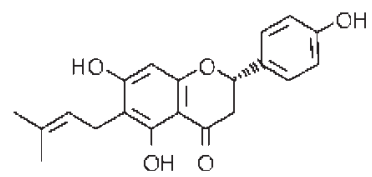

6-Prenylnaringenin (6-PN)

Fig. 1 Prenylflavanones contained in hops and hop extracts.

\section{Experimental Data}

\section{Effectiveness of hop flavanones in preventing osteoporosis}

One of the most prominent physiological effects of the hormonal decline associated with menopause is the loss of bone mass ultimately leading to osteoporosis. It has been shown that in addition to hop-derived rho iso-alpha acids [20,21], all major hop flavanones 8-PN, 6-PN, XH, and IXH possess E2-like effects on osteogenic differentiation in vitro [22].

Concerning the in vivo situation, one of the first publications on 8-PN elucidated its effect on bone mineral density (BMD) of ovariectomized (ovx) rats following 14 days of treatment. It showed that a dose of $30 \mathrm{mg} / \mathrm{kg}$ body weight/day starting at the second day after ovx resulted in an even higher BMD than that observed in sham-operated untreated animals, while untreated ovx animals had reduced BMD. Hümpel et al. demonstrated a dose-dependent inhibition of ovx-induced bone loss in rats following s.c. treatment with $18 \mathrm{mg} / \mathrm{kg}$ 8-PN over a period of 28 days [23]. Since hop contains about equal amounts of both $2 \mathrm{~S}(-)$ and $2 \mathrm{R}(+)$ 8-PN enantiomers, the second part of this study compared effects of the racemic mixture to those of $2 \mathrm{~S}(-)-8$-PN alone. No significant difference was observed indicating that both enantiomers are nearly equally potent at preventing menopause-induced bone loss. More recent work also suggests improved biomechanical properties due to increased bmp when 8-PN is taken up orally as a food content [24]. Interestingly, in this study the effect of 8-PN on these parameters was much larger than that of genistein or resveratrol.

\section{Alleviation of hot flashes by 8-PN}

Vasomotoric climacteric complaints like hot flashes and sweating are thought to be caused by a small increase in core body temperature in conjunction with a narrowing of the thermoneutral zone that describes the range of the body temperature in which no shivering or sweating occurs [25]. These processes are regulated by the thermoregulatory nucleus in the anterior hypothalamus. The only common experimental model to investigate the potency of a drug to alleviate hot flashes is the measurement of differences in tail skin temperature (TST) of ovx rats. While intact rats display a marked decrease of TST during the active phase, this response is lost in ovx animals. This can be reverted by treatment with either estrogens or the $\alpha$-adrenoceptor agonist clonidine which is widely used for the treatment of hot flashes in patients for whom hormone replacement therapy is contraindicated, suggesting that both irregularities in thermoregulation are triggered by a similar mechanism [26]. Using this in vivo model, 8-PN has been shown to restore normal TST after 5 days of treatment with the relatively low dose of $400 \mu \mathrm{g} / \mathrm{kg}$ per day s.c. as well as after oral treatment with $7.5 \mathrm{mg} / \mathrm{animal} / \mathrm{day}$, indicating that 8 -PN may indeed be able to alleviate climacteric hot flashes [27].

\section{Influence on sexual motivation}

Although difficult to differentiate from general age-related effects, sexual motivation seems to decrease due to menopause [28]. One possibility to test sexual motivation in animals is the so-called partner preference test [29]. According to Di Viesta et al., oral treatment of female rats with hop extract dose-dependently decreases the number and cumulative time of visits to a female stimulus animal although the number and time of visits to a male stimulus animal is increased slightly. In addition, perceptive behavior was increased dose-dependently in general, but lordosis was unaffected [30]. This hints at the potency of this extract to improve at least some aspects of sexual motivation. On the other hand pure hop secondary metabolites have not been tested so far.

\section{Clinical Data}

Clinical data are essential to assess the effectiveness as well as the safety of hop extracts and 8-PN for the treatment of menopausal discomforts.

One small clinical trial assessed pharmacokinetics, endocrine effects, and tolerability of a single dose of 50,250 , or $750 \mathrm{mg} 8$-PN in healthy postmenopausal women. It demonstrated that 8-PN is quickly and completely resorbed in the human intestine and that relevant plasma levels are achieved. This was inferred from a decrease of LH levels, an effect assumed to be necessary for the successful treatment of menopausal symptoms [31].

For the first prospective clinical study assessing the effectiveness of a hop extract against climacteric complaints, 67 women between 45 and 60 years of age were treated for 12 weeks with capsules containing either placebo or hop extract standardized to a dose of $100 \mu \mathrm{g} /$ day or $250 \mu \mathrm{g} /$ day 8 -PN, identical to that contained in the food supplement MenoHop. Results show that hop extract may be somewhat effective in treating menopausal discomforts especially against hot flushes, but no clear dose-response correlation could be demonstrated [32].

In a subsequent crossover pilot study by the same group, the effectiveness of hop extract as a drug to relieve menopausal complaints was tested in more detail. And although the number of participants was very low, the outcome also showed a slight improvement of menopause-related symptoms [33]. Interestingly, both hop extract and placebo treatment led to an improvement after eight weeks of treatment, but the subsequent treatment swap led to a further improvement only in the active-treatment-after-placebo group, while the women in the placeboafter-active-treatment group experienced a slight regression of all outcome measures.

Another study assessed the efficacy and safety of vaginal application of a gel containing hop extract among others in postmeno- 
pausal women with urogenital atrophy. Unfortunately, this study was noncontrolled, making it hard to draw solid conclusions [34]. Taken together, evidence for the effectiveness of hop extracts from clinical studies is still very weak. The number of participants in these studies was very low. In addition, the outcome was inevitably based on questionnaire data. These are subjective, and in the case of the Kupperman index, outdated, incomplete and include an arbitrary weighting of the queried symptoms [35]. No clinical information is available on the effects of hop extracts on factors associated with osteoporosis even though the effects of 8-PN on bone are among the more pronounced in cell culture as well as in animal experiments, and there have been no trials conducted so far using pure 8-PN instead of hop extract.

In contrast to classical hormone therapy, for which there is a plethora of prospective and retrospective studies with very large patient numbers [36-41], there is very little information on the safety of hop extracts or 8-PN treatment. It is known that 8-PN is an ER $\alpha$ agonist [42], and proliferative, cancer-promoting effects of estrogens are predominantly mediated by this ER subtype. Uterotrophic assays demonstrate only a mild effect of 8-PN on the uterus wet weight $[7,8]$, but evidence for long-term safety of hop extracts and 8-PN in particular is very weak except for a 90day feeding experiment with ovariectomized rats where 8-PN affected uterine wet weight as well as uterine and mammary histology similar to E2, albeit much weaker [43]. In addition, in silico analysis of hop extract constituents identified a number of substances that are potentially hepatotoxic [44].

\section{Conclusion}

It has been shown that the soy constituent genistein, which is by far the most thoroughly investigated phytoestrogen, is not a good substitute for classical HT, since its effectiveness is dependent on lifelong exposure, but the studies reviewed here indicate that hop extracts may be more promising. While the estrogenicity of the main constituent 8-PN is well established [1,3-5, 8, 45], the in vitro and in vivo experimental data on the effectiveness of hop extracts on climacteric symptoms is so far limited to osteoporosis, hot flashes, and to some degree sexual motivation. There is no high quality clinical data on the effectiveness and safety of hop extracts or 8-PN. An even less characterized alternative to 8-PN may be the structurally very similar flavanone 6-(1,1dimethylallyl)naringenin which has been isolated from the African tree Monotes engleri. While this compound is also a potent ER agonist, it does not possess selectivity for ER $\alpha$ (unpublished data) and appears not to be uterotrophic [8]. This has to be seen as an advantage with regard to safety as tumor promotion should be a smaller concern with this substance.

\section{Acknowledgements}

This work has been supported by the Deutsche Forschungsgemeinschaft DFG KR 3768/2-1.

\section{Conflict of Interest \\ $\nabla$}

All authors declare that they have no conflict of interest.

\section{References}

1 Milligan SR, Kalita JC, Heyerick A, Rong H, Cooman LD, Keukeleire DD. Identification of a potent phytoestrogen in hops (Humulus lupulus L.) and beer. J Clin Endocrinol Metab 1999; 84: 2249-2249

2 Vlietinck AJ. Assessment report for herbal substance(s), herbal preparation(s) or combinations thereof with traditional use - Humulus lupulus L., flos. London: EMEA; 2008

3 Milligan SR, Kalita JC, Pocock V, Kauter VVD, Stevens JF, Deinzer ML, Rong $H$, Keukeleire $D D$. The endocrine activities of 8-prenylnaringenin and related hop (Humulus lupulus L.) flavonoids. J Clin Endocrinol Metab 2000; 85: 4912-4915

4 Milligan S, Kalita J, Pocock V, Heyerick A, Cooman LD, Rong H, Keukeleire $D D$. Oestrogenic activity of the hop phyto-oestrogen, 8-prenylnaringenin. Reproduction 2002; 123: 235-242

5 Zierau O, Gester S, Schwab P, Metz P, Kolba S, Wulf M, Vollmer G. Estrogenic activity of the phytoestrogens naringenin, 6-(1,1-dimethylallyl) naringenin and 8-prenylnaringenin. Planta Med 2002; 68: 449-451

6 Schaefer O, Hümpel M, Fritzemeier KH, Bohlmann R, Schleuning WD. 8Prenyl naringenin is a potent ER $\alpha$ selective phytoestrogen present in hops and beer. J Steroid Biochem Mol Biol 2003; 84: 359-360

7 Diel P, Thomae RB, Caldarelli A, Zierau O, Kolba S, Schmidt S, Schwab P, Metz P, Vollmer G. Regulation of gene expression by 8-prenylnaringenin in uterus and liver of Wistar rats. Planta Med 2004; 70: 39-44

8 Zierau O, Kretzschmar G, Möller F, Weigt C, Vollmer G. Time dependency of uterine effects of naringenin type phytoestrogens in vivo. Mol Cell Endocrinol 2008; 294: 92-99

9 Kitaoka M, Kadokawa H, Sugano M, Ichikawa K, Taki M, Takaishi S, lijima Y, Tsutsumi S, Boriboon M, Akiyama T. Prenylflavonoids: a new class of non-steroidal phytoestrogen (Part 1). Isolation of 8-isopentenylnaringenin and an initial study on its structure-activity relationship. Planta Med 2007; 64: 511-515

10 Komatsu M, Yokoe I, Shirataki Y. Studies on the constituents of Sophora species. XIII. Constituents of the aerial parts of Sophora tomentosa L. Chem Pharm Bull (Tokyo) 1978; 26: 3863-3870

11 Bohlmann F, Zdero C, King RM, Robinson H. New prenylflavanoids from Marshallia grandiflora. Phytochemistry 1979; 18: 1246-1247

12 Chadwick LR, Nikolic D, Burdette JE, Overk CR, Bolton JL, van Breemen RB, Fröhlich R, Fong HHS, Farnsworth NR, Pauli GF. Estrogens and congeners from spent hops (Humulus lupulus). J Nat Prod 2004; 67: 2024-2032

13 Chadwick LR, Pauli GF, Farnsworth NR. The pharmacognosy of Humulus lupulus L. (hops) with an emphasis on estrogenic properties. Phytomedicine 2006; 13: 119-131

14 Stevens JF, Miranda CL, Buhler DR, Deinzer ML. Chemistry and biology of hop flavonoids. JASBC 1998; 56: 136-145

15 Stevens JF, Taylor AW, Deinzer ML. Quantitative analysis of xanthohumol and related prenylflavonoids in hops and beer by liquid chromatography-tandem mass spectrometry. J Chromatogr A 1999; 832: 97 107

16 Possemiers S, Heyerick A, Robbens V, De Keukeleire D, Verstraete W. Activation of proestrogens from hops (Humulus lupulus L.) by intestinal microbiota; conversion of isoxanthohumol into 8-prenylnaringenin. J Agric Food Chem 2005; 53: 6281-6288

17 Possemiers S, Bolca S, Grootaert C, Heyerick A, Decroos K, Dhooge W, Keukeleire DD, Rabot $S$, Verstraete $W$, Wiele de TV. The prenylflavonoid isoxanthohumol from hops (Humulus lupulus L.) is activated into the potent phytoestrogen 8-prenylnaringenin in vitro and in the human intestine. J Nutr 2006; 136: 1862-1867

18 Guo J, Nikolic D, Chadwick LR, Pauli GF, van Breemen RB. Identification of human hepatic cytochrome P450 enzymes involved in the metabolism of 8-prenylnaringenin and isoxanthohumol from hops (Humulus lupulus L.). Drug Metab Dispos 2006; 34: 1152-1159

19 Bolca S, Possemiers S, Maervoet V, Huybrechts I, Heyerick A, Vervarcke S, Depypere H, De Keukeleire D, Bracke M, De Henauw S, Verstraete W, Van de Wiele T. Microbial and dietary factors associated with the 8-prenylnaringenin producer phenotype: a dietary intervention trial with fifty healthy post-menopausal Caucasian women. Br J Nutr 2007; 98: 950959

20 Holick MF, Lamb JJ, Lerman RH, Konda VR, Darland G, Minich DM, Desai A, Chen TC, Austin M, Kornberg J, Chang JL, Hsi A, Bland JS, Tripp ML. Hop rho iso-alpha acids, berberine, vitamin D3 and vitamin K1 favorably impact biomarkers of bone turnover in postmenopausal women in a 14-week trial. J Bone Miner Metab 2010; 28: 342-350

21 Lamb JJ, Holick MF, Lerman RH, Konda VR, Minich DM, Desai A, Chen TC, Austin M, Kornberg J, Chang JL, Hsi A, Bland JS, Tripp ML. Nutritional supplementation of hop rho iso-alpha acids, berberine, vitamin $\mathrm{D}_{3}$, and vi- 
tamin $\mathrm{K}_{1}$ produces a favorable bone biomarker profile supporting healthy bone metabolism in postmenopausal women with metabolic syndrome. Nutr Res 2011; 31: 347-355

22 Ming LG, Ge BF, Wang MG, Chen KM. Comparison between 8-prenylnarigenin and narigenin concerning their activities on promotion of rat bone marrow stromal cells' osteogenic differentiation in vitro. Cell Prolif 2012; 45: 508-515

23 Hümpel M, Isaksson P, Schaefer O, Kaufmann U, Ciana P, Maggi A, Schleuning $W$-D. Tissue specificity of 8-prenylnaringenin: protection from ovariectomy induced bone loss with minimal trophic effects on the uterus. J Steroid Biochem Mol Biol 2005; 97: 299-305

24 Sehmisch S, Hammer F, Christoffel J, Seidlova-Wuttke D, Tezval M, Wuttke W, Stuermer K, Stuermer E. Comparison of the phytohormones genistein, resveratrol and 8-prenylnaringenin as agents for preventing osteoporosis. Planta Med 2008; 74: 794-801

25 Freedman RR. Hot flashes: behavioral treatments, mechanisms, and relation to sleep. Am J Med 2005; 118: 124-130

26 Berendsen HH, Weekers AH, Kloosterboer HJ. Effect of tibolone and raloxifene on the tail temperature of oestrogen-deficient rats. Eur J Pharmacol 2001; 419: 47-54

27 Bowe J, Li XF, Kinsey-Jones J, Heyerick A, Brain S, Milligan S, O'Byrne K. The hop phytoestrogen, 8-prenylnaringenin, reverses the ovariectomy-induced rise in skin temperature in an animal model of menopausal hot flushes. J Endocrinol 2006; 191: 399-405

28 Dennerstein L, Alexander JL. The menopause and sexual functioning. Annu Rev Sex Res 2003; 14: 64-82

29 Ågmo A, Turi AL, Ellingsen E, Kaspersen H. Preclinical models of sexual desire: conceptual and behavioral analyses. Pharmacol Biochem Behav 2004; 78: 379-404

30 Di Viesti V, Carnevale G, Zavatti M, Benelli A, Zanoli P. Increased sexual motivation in female rats treated with Humulus lupulus L. extract. J Ethnopharmacol 2011; 134: 514-517

31 Rad M, Hümpel M, Schaefer O, Schoemaker RC, Schleuning WD, Cohen AF, Burggraaf J. Pharmacokinetics and systemic endocrine effects of the phyto-oestrogen 8-prenylnaringenin after single oral doses to postmenopausal women. Br J Clin Pharmacol 2006; 62: 288-296

32 Heyerick A, Vervarcke S, Depypere $H$, Bracke M, Keukeleire DD. A first prospective, randomized, double-blind, placebo-controlled study on the use of a standardized hop extract to alleviate menopausal discomforts. Maturitas 2006; 54: 164-175

33 Erkkola $R$, Vervarcke S, Vansteelandt S, Rompotti P, De Keukeleire D, Heyerick $A$. A randomized, double-blind, placebo-controlled, crossover pilot study on the use of a standardized hop extract to alleviate menopausal discomforts. Phytomedicine 2010; 17: 389-396
34 Morali G, Polatti F, Metelitsa E, Mascarucci P, Magnani P, Brunenghi Marrè G. Open, non-controlled clinical studies to assess the efficacy and safety of a medical device in form of gel topically and intravaginally used in postmenopausal women with genital atrophy. Arzneimittelforschung 2011; 56: 230-238

35 Alder E. The Blatt-Kupperman menopausal index: a critique. Maturitas 1998; 29: 19-24

36 Rossouw JE, Anderson GL, Prentice RL, LaCroix AZ, Kooperberg C, Stefanick ML, Jackson RD, Beresford SAA, Howard BV, Johnson KC, Kotchen $J M$, Ockene J. Risks and benefits of estrogen plus progestin in healthy postmenopausal women: principal results From the Women's Health Initiative randomized controlled trial. JAMA 2002; 288: 321-333

37 Beral V, Banks E, Reeves $G$. Evidence from randomised trials on the longterm effects of hormone replacement therapy. The Lancet 2002; 360 : 942-944

38 Beral V. Breast cancer and hormone-replacement therapy in the Million Women Study. The Lancet 2003; 362: 419-427

39 Beral V. Ovarian cancer and hormone replacement therapy in the Million Women Study. The Lancet 2007; 369: 1703-1710

40 Chlebowski RT, Hendrix SL, Langer RD, Stefanick ML, Gass M, Lane D, Rodabough RJ, Gilligan MA, Cyr MG, Thomson CA, Khandekar J, Petrovitch $H$, McTiernan A. Influence of estrogen plus progestin on breast cancer and mammography in healthy postmenopausal women: The Women's Health Initiative Randomized Trial. JAMA 2003; 289: 3243-3253

41 Chlebowski RT, Kuller LH, Prentice RL, Stefanick ML, Manson JE, Gass M, Aragaki AK, Ockene JK, Lane DS, Sarto GE, Rajkovic A, Schenken R, Hendrix SL, Ravdin PM, Rohan TE, Yasmeen S, Anderson G. Breast cancer after use of estrogen plus progestin in postmenopausal women. N Engl J Med 2009; 360: 573-587

42 Overk CR, Yao P, Chadwick LR, Nikolic D, Sun Y, Cuendet MA, Deng Y, Hedayat AS, Pauli GF, Farnsworth NR, van Breemen RB, Bolton JL. Comparison of the in vitro estrogenic activities of compounds from hops $(\mathrm{Hu}$ mulus lupulus) and red clover (Trifolium pratense). J Agric Food Chem 2005; 53: 6246-6253

43 Rimoldi G, Christoffel J, Wuttke W. Morphologic changes induced by oral long-term treatment with 8-prenylnaringenin in the uterus, vagina, and mammary gland of castrated rats. Menopause 2006; 13: 669-677

44 Wang YJ, Dou J, Cross KP, Valerio Jr. LG. Computational analysis for hepatic safety signals of constituents present in botanical extracts widely used by women in the United States for treatment of menopausal symptoms. Regul Toxicol Pharmacol 2011; 59: 111-124

45 Kretzschmar G, Zierau O, Wober J, Tischer S, Metz P, Vollmer G. Prenylation has a compound specific effect on the estrogenicity of naringenin and genistein. J Steroid Biochem Mol Biol 2010; 118: 1-6 